\title{
Sex differences in temperature-related all-cause mortality in the Netherlands
}

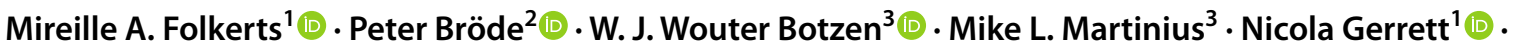 \\ Carel N. Harmsen ${ }^{4} \cdot$ Hein A. M. Daanen ${ }^{1}$
}

Received: 11 January 2021 / Accepted: 25 April 2021 / Published online: 5 June 2021

(c) The Author(s) 2021

\begin{abstract}
Purpose Over the last few decades, a global increase in both cold and heat extremes has been observed with significant impacts on human mortality. Although it is well-identified that older individuals ( $>65$ years) are most prone to temperaturerelated mortality, there is no consensus on the effect of sex. The current study investigated if sex differences in temperaturerelated mortality exist in the Netherlands.

Methods Twenty-three-year ambient temperature data of the Netherlands were combined with daily mortality data which were subdivided into sex and three age classes ( $<65$ years, 65-80 years, $\geq 80$ years). Distributed lag non-linear models were used to analyze the effect of ambient temperature on mortality and determine sex differences in mortality attributable to the cold and heat, which is defined as mean daily temperatures below and above the Minimum Mortality Temperature, respectively.

Results Attributable fractions in the heat were higher in females, especially in the oldest group under extreme heat $(\geq 97.5$ th percentile), whilst no sex differences were found in the cold. Cold- and heat-related mortality was most prominent in the oldest age group ( $\geq 80$ years) and to a smaller extent in the age group between $65-80$ years. In the age group $<65$ years temperature-related mortality was only significant for males in the heat.

Conclusion Mortality in the Netherlands represents the typical V- or hockey-stick shaped curve with a higher daily mortality in the cold and heat than at milder temperatures in both males and females, especially in the age group $\geq 80$ years. Heatrelated mortality was higher in females than in males, especially in the oldest age group ( $\geq 80$ years) under extreme heat, whilst in the cold no sex differences were found. The underlying cause may be of physiological or behavioral nature, but more research is necessary.
\end{abstract}

Keywords Mortality $\cdot$ Temperature $\cdot$ Climate change $\cdot$ Sex differences

Hein A. M. Daanen

h.a.m.daanen@vu.nl

1 Department of Human Movement Sciences, Faculty of Behaviour and Movement Sciences, Vrije Universiteit Amsterdam, Amsterdam Movement Sciences, Van der Boechorststraat 7-9, 1081 BT Amsterdam, The Netherlands

2 Leibniz Research Centre for Working Environment and Human Factors (IfADo), Dortmund, Germany

3 Institute for Environmental Studies (IVM), Vrije Universiteit Amsterdam, De Boelelaan 1087, 1081 HV Amsterdam, The Netherlands

4 Statistics Netherlands, Voorburg, The Netherlands

\section{Introduction}

A global increase in heat waves and cold spells have been observed over the last few decades and this increase is expected to continue due to climate change (Alexander et al. 2006; Meehl and Tebaldi 2004; Rahmstorf and Coumou 2011). Although mild cold is reportedly the dominating cause of temperature-related mortality worldwide (Gasparrini et al. 2015), thermal extremes have a profound effect on morbidity and mortality, mostly due to cardiovascular or respiratory failure (Analitis et al. 2008; Baccini et al. 2008; Costello et al. 2009). To inform policies that aim to reduce temperature-related mortality, it is important to know which subgroups of the population are especially vulnerable to this cause of death. For example, it is well known that the 
elderly population are most at risk for temperature-related morbidity and mortality, as their thermoregulatory function is impaired, they are often less physically fit and have more chronic illnesses and diseases (Koppe et al. 2004; Worfolk 2000).

Besides an age-related increase in risk for temperaturerelated morbidity and mortality, there might also be sexrelated differences. Males and females differ from each other in their physiology, anthropometric characteristics, body composition and social behavior, which impact their thermoregulation (Gagnon and Kenny 2012; Kaciuba-Uscilko and Grucza 2001). Females tend to have a disadvantage in the heat due to the larger body surface to mass ratio, greater body fat percentage and lower exercise capacity (KaciubaUscilko and Grucza 2001). Furthermore, in hot conditions, females have a decreased heat dissipation compared to males during intense exercise due to a lower sweating capacity (Yanovich et al. 2020). In the cold, females are at a slight advantage due to their greater body fat content which functions as insulation (Kaciuba-Uscilko and Grucza 2001; McArdle et al. 1992). A higher heat-related mortality for females and a higher cold-related mortality for males is expected due to the aforementioned physiological differences.

A number of studies investigating temperature-related mortality suggest sex is a contributing factor, with females to be more at risk during the heat than males ( $₫$ ström et al. 2011; Basu 2009; van Steen et al. 2019). However, this is not fully supported in the literature (Åström et al. 2011; Basu 2009; Jiao et al. 2019; Rocklöv et al. 2014; van Steen et al. 2019). In Stockholm County (Sweden), Hong Kong (China) and Wuhan (China) a higher mortality amongst males was reported in the heat (Jiao et al. 2019; Liu et al. 2020; Rocklöv et al. 2014). In different regions in Spain, three studies reported contrasting outcomes regarding sex differences in the heat. In Galicia, a higher mortality was reported amongst females (DeCastro et al. 2011), whilst in Catalonia no sex differences were reported (Basagaña et al. 2011). In Madrid, a higher mortality amongst males in the age group between 65-75 years, and higher mortality in females in the age group older than 75 years, were reported (Díaz et al. 2002). In Hong Kong (China), Stockholm County (Sweden) and Cyprus, higher mortality in males was reported in the cold (Liu et al. 2020; Pyrgou and Santamouris 2020; Rocklöv et al. 2014), while in South East England a higher mortality in females was reported (Donaldson et al. 2019). In seven USA cities (Denver, Detroit, Minneapolis, New Haven, Pittsburgh and Chicago, and Seattle) no difference between males and females was found in the cold (O'Neill et al. 2003). Differences in temperature-related mortality between studies executed in different cities and countries may be partly related to geographical location and differences in the building environment. A previous study showed that the
Minimum Mortality Temperature (MMT) is depended on geographical location with southern European cities having a higher MMT than northern European cities (Krummenauer et al. 2019). Urban areas are hotter than rural areas and in cities with tall and high density buildings with a lack of green spaces, temperatures can increase significantly more than in cities surrounded with rural areas and low buildings (Koppe et al. 2004). Furthermore, structure and insulation of buildings differ between countries, which can influence the effect outdoor temperature has on the indoor temperature where people spend most of their time (Klepeis et al. 2001). However, this does not explain the lack of consensus in the literature on sex differences in temperature-related mortality, since the distribution of males and females within a city is similar. Furthermore, less information is available about the sex differences in mortality in the cold than in the heat. Therefore, the aim of the current study was to add information to the limited and sometimes contradictory pool of data on sex differences in temperature-related mortality by analyzing a large dataset based on 23 years (1995 till 2017) of daily temperature and mortality in the Netherlands.

\section{Methods}

\section{Data sources}

Daily mortality in the Netherlands between 1 January 1995 and 31 December 2017 was obtained from Statistics Netherlands. The data contain the daily all-cause mortality for the total Dutch population and is subdivided into sex and three age classes: $<65$ years, $65-80$ years, $\geq 80$ years. Daily population size for the different sexes and age classes were also included in the dataset. Temperature data were obtained from the Royal Netherlands Meteorological Institute. Hourly ambient temperature was derived from the five main weather stations throughout the Netherlands (De Bilt; Rotterdam; Schiphol Airport; Eelde and Maastricht) and averaged over time and space into average daily temperature. For the Netherlands this approach seemed acceptable as the Netherlands is rather small, $300 \mathrm{~km}$ from north to south and $200 \mathrm{~km}$ from west to east. Maximum distance from a household to the closest weather station included in the study is $100 \mathrm{~km}$. Correlations of the measured temperatures between the included weather stations is very high: namely $r>0.967$. Other studies performed in the Netherlands investigating mortality and temperature used the same approach with averaged daily temperature (Botzen et al. 2020; Ekamper et al. 2009; Huynen and Martens 2015), which gives confidence in our approach for the Netherlands. 


\section{Statistical analysis}

Data were analyzed in the statistical software $\mathrm{R}$ version 3.6.1. Time series of daily death counts for males and females divided into the three age classes were analyzed separately by quasi-Poisson regression allowing for over dispersion (Wood 2006). Distributed lag non-linear models (DLNM) were fitted using the dlnm package (Gasparrini 2011) applying natural cubic spline functions with eight degrees-of-freedom per year for adjusting for seasonality and long-term trend. To consider non-linear temperature effects, a quadratic B-spline function with four degrees-offreedom was used with two equally distributed internal knots placed at $0.8^{\circ} \mathrm{C}$ and $13.8^{\circ} \mathrm{C}$ in combination with another spline function with three logarithmically equally distributed knots to model lagged temperature effects up to 20 days (Gasparrini and Leone 2014). In addition, day-of-week was included as covariate and log population size as offset, i.e. as predictor with coefficient fixed to one.

Mortality due to the cold or heat is quantified by attributable fractions, which is the excess mortality calculated from the Minimum Mortality Temperature (MMT) (Gasparrini and Leone 2014). The MMT is the mean daily temperature at which the lowest mortality occurs and quantifies the threshold between the cold and heat mortality slope (Folkerts et al. 2020). The MMT with SE was calculated by a search algorithm over the fitted response function (Tobías et al. 2017), which was applied separately for the time series defined by sex and age group. Heat is defined as ambient temperatures higher than the MMT and cold is defined as ambient temperatures lower than the MMT. A subdivision is made between mild and extreme cold and heat mortality attributable fractions, where mild cold and heat mortality attributable fractions are defined as the mortality between the MMT and 2.5th/97.5th percentile of the mean daily temperature, and extreme cold and heat mortality attributable fractions below and above the 2.5th/97.5th percentile (Gasparrini et al. 2015).

From the calculated attributable fractions with SE, the presence of temperature-related mortality was deduced in case the attributable fraction 95\% confidence interval (CI) did not include zero. The significance of sex as potential modifier of cold- and heat-related mortality was assessed by inspection of the confidence intervals for males and females.

\section{Results}

Table 1 shows the descriptive statistics of daily mortality in the Netherlands between 1995-2017. In the Netherlands, females reach an older age than males as can be seen by the population sizes in Table 1. Furthermore, the mean age of females is slightly higher than males; $+0.3,+0.4,+1.0$ yea rs for the age groups $<65,65-80, \geq 80$ years, respectively. Therefore, daily mortality per 100,000 residents of the same sex and similar age provides a better overview of sex differences in temperature-related mortality.

Mortality due to the cold was greater than to the heat in both males and females. In the cold there was an increase in mortality from the MMT to the 2.5th percentile for males of $14.7 \%$ and for females of $18.3 \%$. In the heat the increase in mortality from the MMT to the 97.5th percentile was $8.0 \%$ for males and $14.3 \%$ for females. The highest increase in mortality was in the oldest age group ( $\geq 80$ years) with an increase for males and females of $19.2 \%$ and $21.9 \%$ respectively in the cold, and of $14.6 \%$ and $21.2 \%$ respectively in the heat. Especially in the heat there was a large difference between the oldest age group ( $\geq 80$ years) and the age groups $<65$ and $65-80$ years. This is also shown in Figs. 1 and 2. Figure 1 shows the overall exposure-response associations of daily mean temperature $\left({ }^{\circ} \mathrm{C}\right)$ and daily mortality cumulating all lagged effects in the Netherlands between 1995-2017. Figure 2 shows the daily mortality attributable fractions in the heat and cold in the Netherlands between 1995 and 2017. Data are subdivided into males and females for the total population and separated for three different age groups ( $<65,65-80, \geq 80$ years). In the age group $<65$ years temperature-related mortality was non-significant; only for males in the heat, there appears to be a small temperature effect on mortality, which was comparable in size to that for males aged $65-80$ years.

Overall mortality per 100,000 residents was higher in males in the heat for the age groups $65-80$ years and $\geq 80$ years (Table 1 ), but the increase in mortality from the MMT was higher for females with $4.0 \%$ and $4.4 \%$ in the age group $65-80$ years and $14.6 \%$ and $21.1 \%$ in the age group $\geq 80$ years for males and females respectively. Inspecting the confidence intervals for males and females in Fig. 2 indicates that in mild and extreme heat for the total population the differences between males and females were significant, but age-specific differences were significant only for the age group $\geq 80$ years in extreme heat. No significant differences occurred in cold-related mortality between males and females.

\section{Discussion}

Mortality in the Netherlands represents the typical V- or hockey-stick shaped curve with a higher daily mortality in the cold and heat than at milder temperatures in both males and females, especially in the age group $\geq 80$ years. There were no sex differences in cold-related mortality in this study, but females appear to be more susceptible than males to both mild and extreme heat when considering all age groups combined. This is still the case after correcting for 


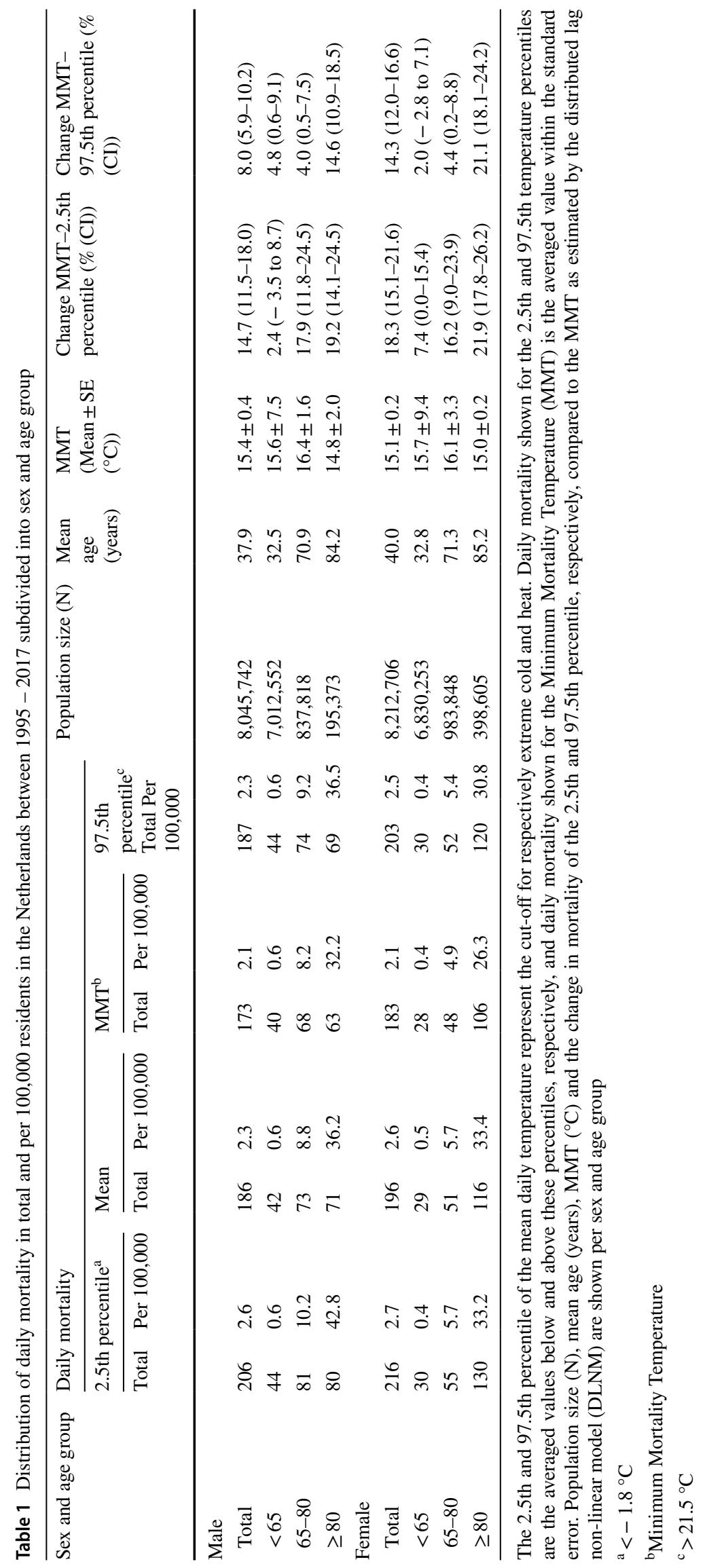


Fig. 1 The overall cumulative exposure-response associations of daily mean temperature $\left({ }^{\circ} \mathrm{C}\right)$ and daily mortality in the Netherlands between 1995-2017 subdivided into males and females for the total population and separated for three different age groups $(<65$, $65-80, \geq 80$ years). The vertical solid lines represent the Minimum Mortality Temperature (MMT) and the dashed lines the 2.5th and 97.5th percentile of the mean daily temperature, respectively. Gray-shaded error bands indicate the $95 \%$ confidence interval
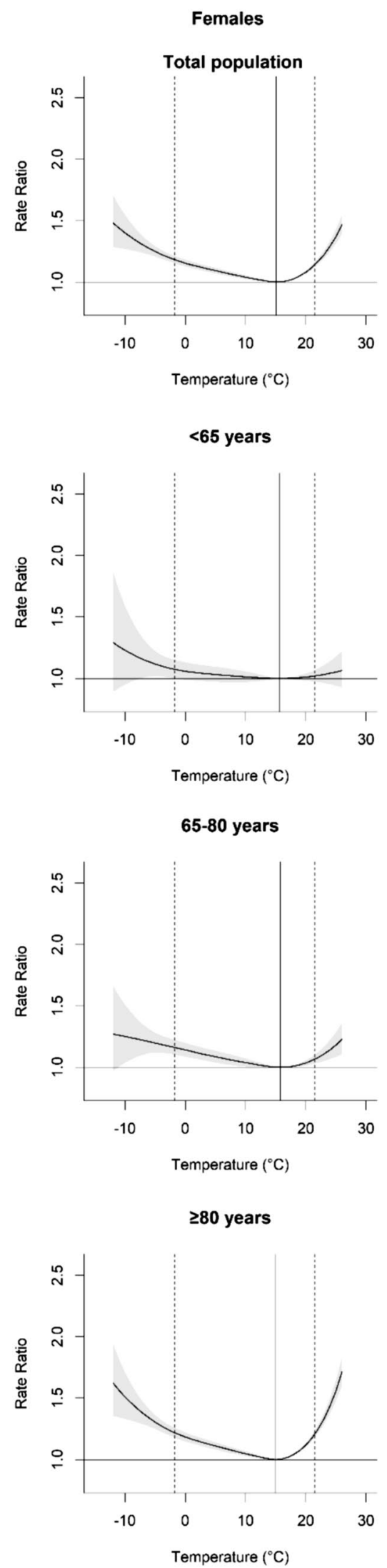

Males

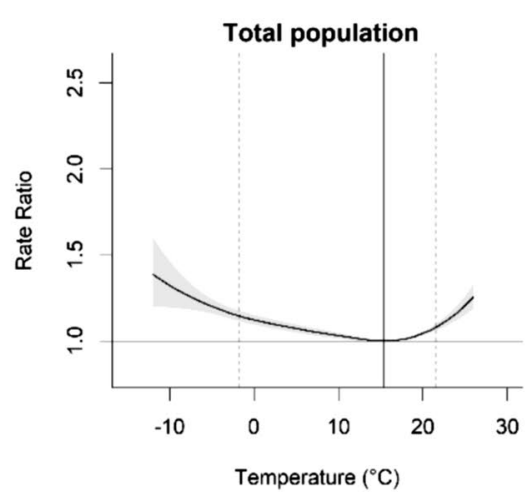

$<65$ years

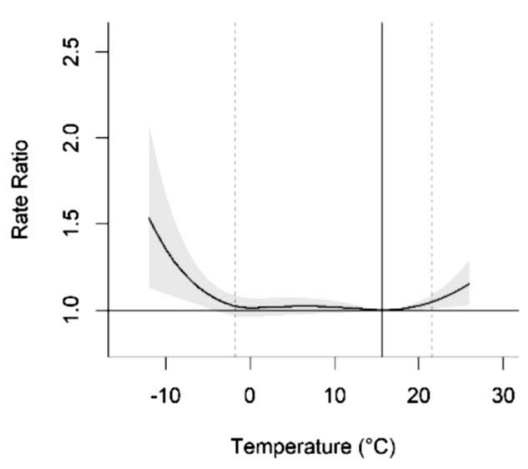

$65-80$ years

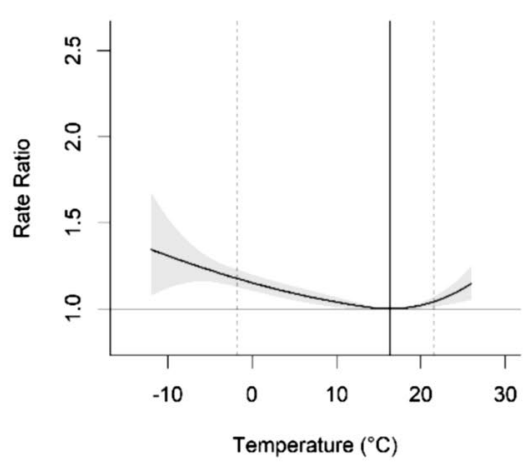

$\geq 80$ years

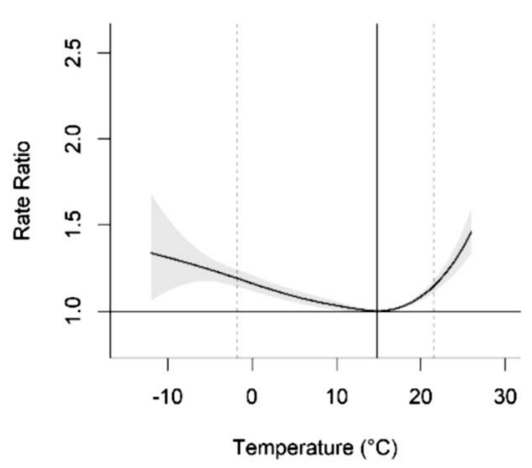



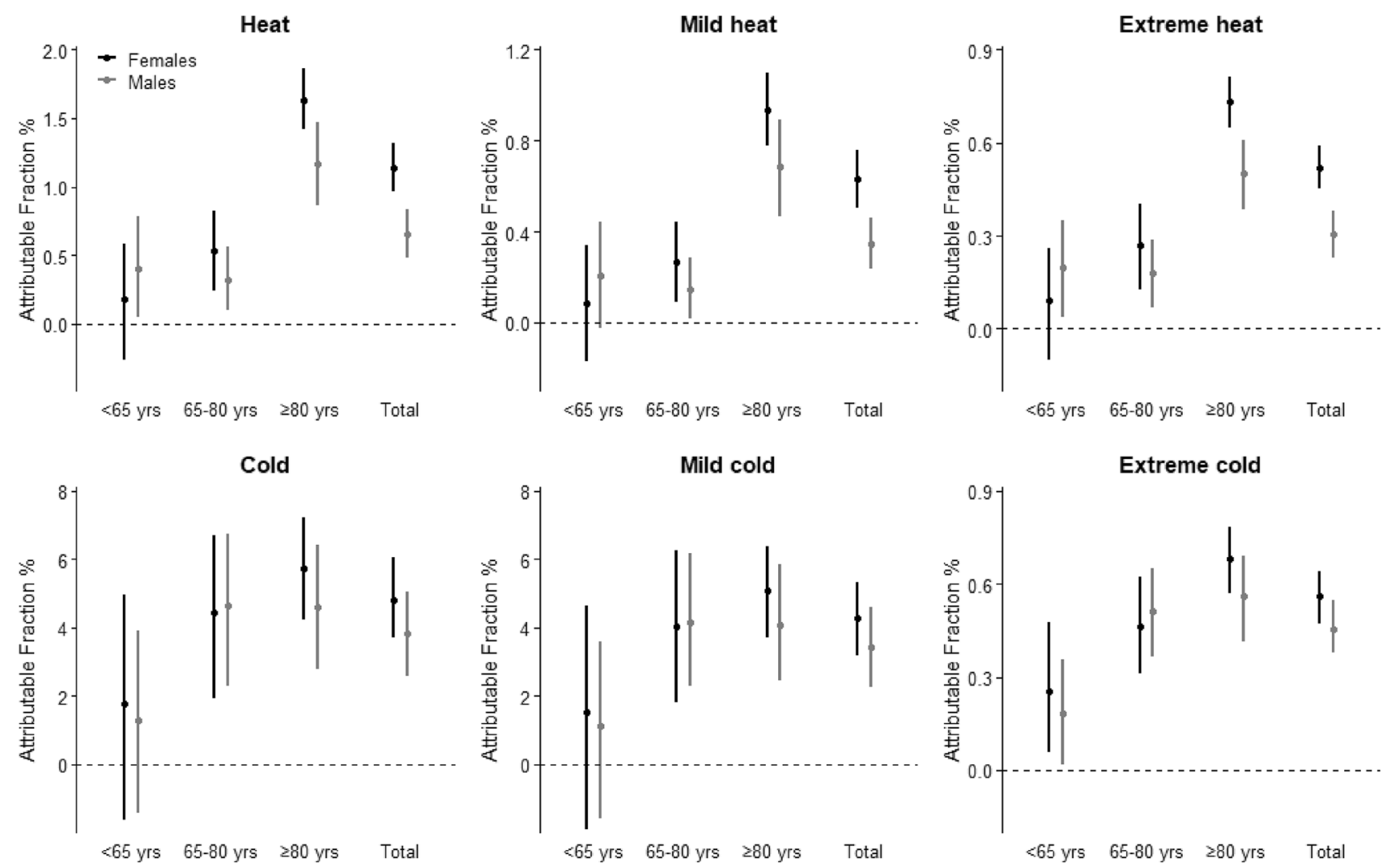

Fig. 2 Daily mortality attributable to the heat and cold in the Netherlands between 1995-2017 subdivided into males and females for the total population and separated for three different age groups $(<65$, $65-80, \geq 80$ years). Heat is defined as ambient temperatures higher than the Minimum Mortality Temperature (MMT) and cold is defined as ambient temperatures lower than the MMT. Mild cold/heat is defined as the temperature between the MMT and 2.5th/97.5th percentile of the mean daily temperature, and extreme cold/heat as the temperature below and above the $2.5^{\text {th }} / 97.5^{\text {th }}$ percentile. Vertical error bars indicate the $95 \%$ confidence interval. Please note that the y-axes are not identically scaled

in previous studies are, for example, Hunan (China), which has a humid subtropical climate, Galicia (Spain), which has a mild oceanic climate and Belgrade (Serbia), which has a continental climate (Bogdanović et al. 2013; Central Intelligence Agency-The World Factbook 2021; DeCastro et al. 2011; Ling-Shuang et al. 2020). To our knowledge, this is the first study to explore sex differences in temperature-related mortality in a temperate marine climate, as observed in the Netherlands. Our results contribute to the existing body of literature and provide evidence that, alongside other climates, females appear to be more vulnerable to heat-related mortality.

The increasing risk for heat-related mortality as people age, may partly be explained by the age-related physiological changes. McGinn et al. (2017) showed that whole-body heat loss decreases with $4 \%$ each decade after the age of 20 years in healthy adults. The reduction in the ability to lose heat with aging is for the largest part explained by the lower overall sweat rate in older adults, as evaporative heat loss is the strongest avenue of heat loss from the human body (Balmain et al. 2018; McArdle et al. 2014). To the 
authors' knowledge, no studies have investigated the agerelated physiological decline between males and females in their ability to lose heat. However, it is known that females sweat less than males, and older females sweat less than younger females, indicating that the ability of older females to lose heat from the body is the lowest (Daanen and Herweijer 2015; Yanovich et al. 2020). Heat puts considerable stress on the cardiovascular system, especially in older individuals who rely on a greater percentage of their maximum heart rate to increase cardiac output during whole-body heat stress than young adults, indicating greater cardiovascular strain (Kenney et al. 2014). Not surprisingly, one of the main causes of heat-related mortality is related to a cardiovascular disorder (Åström et al. 2011). Cardiovascular strain is reportedly higher in females, potentially explaining their higher mortality risk in the heat (Achebak et al. 2019; Yanovich et al. 2020).

Furthermore, the behavior of older males and females may also influence the higher risk for mortality in the heat. It has been reported, that older adults are less willing to use adaptive cooling strategies, potentially due to reduced sensitivity to thermal comfort, lack of social support or not wanting to be seen as 'old' and 'vulnerable' (Tan et al. 2020). Some studies suggest women initiate thermal behavior to cool down earlier and use it to a greater extent than males (Corbett et al. 2020; Vargas et al. 2019). However, these studies are conducted with young subjects and it is not known if this difference still persists in older adults. Van Steen et al. (2019) stated that females often outlive their male partners and therefore live alone, which has been reported as a contributing factor as physical and social isolation is highly correlated to heat-related mortality. It was also reported that females tend to be less active in general, but more active in the household (Lee 2005). Continuing these activities during heat waves while being less physically fit puts females more at risk for overheating and cardiovascular strain than males (van Steen et al. 2019). Furthermore, it was mentioned that females often have a lower income which is associated with less quality housing and often no air conditioning; resulting in higher indoor temperatures (van Steen et al. 2019). In the Netherlands housing quality is generally of a high standard and the houses are well insulated (Planbureau voor de Leefomgeving-Balans van de Leefomgeving 2016). Higher insulation may hamper heat removal during the summer, thus increasing indoor heat stress. However, a previous study showed that insulation only plays a minor role in the risk of overheating and when ventilated proper insulation even lowers the severity and risk of overheating (Fosas et al. 2018). Furthermore, the ownership of air conditioning units is not that common in the Netherlands (The Japan Refrigeration and Air Conditioning Industry Association 2018; Planbureau voor de Leefomgeving-Balans van de
Leefomgeving 2016). Therefore it seems unlikely that a lower income of females will explain the sex differences in heat-related mortality in the Netherlands when considering housing quality and use of air conditioning.

More research is needed to determine these sex differences in heat-related mortality from both a physiological and behavioral perspective. The limited number of physiological studies with female participants may be contributing to our poor understanding of their response to the heat. A better understanding of these differences will allow for better targeted heat policies for both males and females and potentially lower heat-related morbidity and mortality across the general population. For example, in 2007 a heat health warning system (HHWS) was developed in the Netherlands which is activated if there is a high chance of five consecutive days with an ambient temperature exceeding $27{ }^{\circ} \mathrm{C}$ (Casanueva et al. 2019; Lowe et al. 2011). More attention for females in the HHWS could be a next step at decreasing the negative effects of heat for females.

In the cold a significant higher effect on mortality was found for the age groups $65-80$ and $\geq 80$ years, but no sex differences were observed. Cold-related mortality in older adults has mostly a cardiovascular, respiratory, and cerebrovascular origin (Analitis et al. 2008). The observed absence of any sex differences in the cold is in line with a previous study done in the USA (O'Neill et al. 2003). However, other studies have reported a higher mortality in males or females in the cold (Donaldson et al. 2019; Liu et al. 2020; Pyrgou and Santamouris 2020; Rocklöv et al. 2014). Sex differences in the cold seem to be less prominent than in the heat, as there is no consensus in outcome of different studies. Potentially this is the case as the physiological disadvantage of males, e.g. the lower body fat content, can easily be compensated with thermoregulatory behaviors such as adding an extra layer of clothing (Kaciuba-Uscilko and Grucza 2001). A previous study showed that males wear 0.14 clo more than females, suggesting this may indeed be the case (Donaldson et al. 2001). Furthermore, adaptive behavior to the cold may differ between countries and therefore result in different outcomes in mortality. One specific difference in adaptive behavior to the cold between regions is the wearing of gloves, hats and scarfs, which is reported to be less frequent in the southern regions of Europe (Donaldson et al. 2001). Another explanation for the lack of consistency in sex differences in cold-related mortality between studies is the level of income of the elderly population in a country. People with higher incomes can afford better insulated houses and energy to warm their houses in winter, which reduces their exposure to the cold compared to people with lower incomes (McKee 1989). However, not much is known about these potential behavioral differences between countries and future research should focus on this, which could be used to adapt policies regarding behavior in the cold. 


\section{Limitations}

As our analyses concern all-cause mortality only, this limits our interpretation of the specific causes of coldand heat-related mortality. Furthermore, the temperature data of the five weather stations in the Netherlands were averaged and considered to be indicative for the weather conditions in the Netherlands. Ambient temperature at the location where a person passed away can differ from the mean ambient temperature. However, this difference is considered to be minimal in a small country like the Netherlands with a mean standard deviation of $0.7^{\circ} \mathrm{C}$ between weather stations. In the current study only mean ambient temperature is used to represent the thermal environment and no other parameters like humidity and solar radiation. A previous study showed no correlation between mortality and humidity, indicating that potentially humidity had limited influence in the current study as well (Armstrong et al. 2019). However, future studies should focus more in depth what the effect is of different environmental parameters, like humidity and solar radiation, on the higher mortality in females, preferably using data at a regional or local level. Moreover, no correction was made for the mean age of the males and females within each age group. However, as shown in Table 1, mean age within each age group is almost similar. Therefore, it is assumed to have no effect on the reported results.

\section{Conclusion}

Mortality in the Netherlands represents the typical V-or hockey-stick shaped curve with a higher daily mortality in the cold and heat than at milder temperatures in both males and females, especially in the age group $\geq 80$ years. Heatrelated mortality in the Netherlands was higher in females than in males, especially in the oldest age group ( $\geq 80$ years) under extreme heat, whilst in the cold no sex differences were found. The underlying cause may be of physiological or behavioral nature, but more research is necessary.

Author contributions $\mathrm{HD}, \mathrm{MF}, \mathrm{WB}$, and MM devised the study. HD, $\mathrm{MF}$, and $\mathrm{PB}$ designed and conceived the analyses. $\mathrm{CH}, \mathrm{MF}$, and $\mathrm{MM}$ collected and organized the data. MF and $\mathrm{PB}$ performed the statistical analysis. MF and HD wrote the first draft. All authors interpreted the data, and, after critically reviewing and providing significant editing of its content, approved the final manuscript.

Funding The authors acknowledge the funding from the Amsterdam Sustainability Institute and the ClimApp project. Project ClimApp is part of ERA4CS, an ERA-NET initiated by JPI Climate, and funded by FORMAS (SE), IFD (DK), NWO (NL) with co-funding by the European Union (Grant 690462).
Availability of data and material The datasets generated for this study are available on request to the corresponding author.

Code availability The $\mathrm{R}$ script used for this study is available on request to the corresponding author.

\section{Declarations}

Conflict of interest The authors declare no conflict of interest.

Open Access This article is licensed under a Creative Commons Attribution 4.0 International License, which permits use, sharing, adaptation, distribution and reproduction in any medium or format, as long as you give appropriate credit to the original author(s) and the source, provide a link to the Creative Commons licence, and indicate if changes were made. The images or other third party material in this article are included in the article's Creative Commons licence, unless indicated otherwise in a credit line to the material. If material is not included in the article's Creative Commons licence and your intended use is not permitted by statutory regulation or exceeds the permitted use, you will need to obtain permission directly from the copyright holder. To view a copy of this licence, visit http://creativecommons.org/licenses/by/4.0/.

\section{References}

Achebak H, Devolder D, Ballester J (2019) Trends in temperaturerelated age-specific and sex-specific mortality from cardiovascular diseases in Spain: a national time-series analysis the lancet planetary. Health 3:e297-e306. https://doi.org/10.1016/S25425196(19)30090-7

Alexander L et al (2006) Global observed changes in daily climate extremes of temperature and precipitation. J Geophys Res. https:// doi.org/10.1029/2005JD006290

Analitis A et al (2008) Effects of cold weather on mortality: results from 15 European cities within the PHEWE project. Am J Epidemiol 168:1397-1408. https://doi.org/10.1093/aje/kwn266

Armstrong B et al (2019) The role of humidity in associations of high temperature with mortality: a multicountry, multicity study. Environ Health Perspect 127:097007-097008. https://doi.org/10.1289/ EHP5430

Armstrong BG et al (2020) Sample size issues in time series regressions of counts onenvironmental exposures. BMC Med Res Methodol 20:15. https://doi.org/10.1186/s12874-019-0894-6

Åström DO, Forsberg B, Rocklov J (2011) Heat wave impact on morbidity and mortality in the elderly population: a review of recent studies. Maturitas 69:99-105. https://doi.org/10.1016/j.maturitas. 2011.03.008

Baccini M et al (2008) Heat effects on mortality in 15 European cities. Epidemiology 19:711-719. https://doi.org/10.1097/EDE.0b013 e318176bfcd

Balmain BN, Sabapathy S, Louis M, Morris NR (2018) Aging and thermoregulatory control: the clinical implications of exercising under heat stress in older individuals. BioMed Res Int. https://doi. org/10.1155/2018/8306154

Basagaña X et al (2011) Heat waves and cause-specific mortality at all ages. Epidemiology 22:765-772. https://doi.org/10.1097/EDE. 0b013e31823031c5

Basu R (2009) High ambient temperature and mortality: a review of epidemiologic studies from 2001 to 2008. Environ Health 8:40. https://doi.org/10.1186/1476-069X-8-40 
Bettaieb J, Toumi A, Leffondre K, Chlif S, Ben Salah A (2020) High temperature effect on daily all-cause mortality in Tunis 20052007. Rev Epidemiol Sante Publique 68:37-43. https://doi.org/ 10.1016/j.respe.2019.09.007

Bogdanović DĈ, Milošević ZG, Lazarević KK, Dolićanin ZĆ, Randelović DM, Bogdanović SD (2013) The Impact of the july 2007 heat wave on daily mortality in Belgrade, Serbia Central European. J Public Health 21:140-145. https://doi.org/10.21101/ cejph.a3840

Botzen WJW et al (2020) Economic valuation of climate changeinduced mortality: age dependent cold and heat mortality in the Netherlands. Clim Change 162:545-562. https://doi.org/10.1007/ s10584-020-02797-0

Casanueva A et al (2019) Overview of existing heat-health warning systems in Europe. Int J Environ Res Public Health. https://doi. org/10.3390/ijerph16152657

Central Intelligence Agency (2021). The World Factbook. https://www. cia.gov/the-world-factbook/. Accessed 6 Jan 2021

Corbett J, Wright J, Tipton MJ (2020) Sex differences in response to exercise heat stress in the context of the military environment. BMJ Mil Health. https://doi.org/10.1136/jramc-2019-001253

Costello A et al (2009) Managing the health effects of climate change: Lancet and University College London Institute for Global Health Commission. Lancet 373:1693-1733. https:// doi.org/10.1016/S0140-6736(09)60935-1

Daanen HAM, Herweijer JA (2015) Effectiveness of an indoor preparation program to increase thermal resilience in elderly for heat waves. Build Environ 83:115-119. https://doi.org/10.1016/j. buildenv.2014.04.010

DeCastro M, Gomez-Gesteira M, Ramos AM, Álvarez I, DeCastro P (2011) Effects of Heat Waves on Human Mortality, Galicia, Spain. Clim Res 48:333-341. https://doi.org/10.3354/cr00988

Díaz J, Jordán A, García R, López C, Alberdi JC, Hernández E, Otero A (2002) Heat waves in Madrid 1986-1997: effects on the health of the elderly. Int Arch Occup Environ Health 75:163170. https://doi.org/10.1007/s00420-001-0290-4

Donaldson GC, Rintamäki H, Näyhä S (2001) Outdoor clothing: its relationship to geography, climate, behaviour and cold-related mortality in Europe. Int J Biometeorol 45:45-51. https://doi. org/10.1007/s004840000072

Donaldson G, Witt C, Näyhä S (2019) Changes in cold-related mortalities between 1995 and 2016 in South East England. Public Health 169:36-40. https://doi.org/10.1016/j.puhe.2019.01.008

Ekamper P, van Poppel F, van Duin C, Garssen J (2009) 150 years of temperature-related excess mortality in the Netherlands. Demogr Res 21:385-426. https://doi.org/10.4054/DemRes. 2009.21.14

Folkerts MA, Bröde P, Botzen WJW, Martinius ML, Gerrett N, Harmsen CN, Daanen HAM (2020) Long term adaptation to heat stress: shifts in the minimum mortality temperature in the Netherlands. Front Physiol. https://doi.org/10.3389/fphys.2020.00225

Fosas D, Coley DA, Natarajan S, Herrera M, Fosas de Pando M, Ramallo-Gonzalez A (2018) Mitigation versus adaptation: does insulating dwellings increase overheating risk? Build Environ 143:740-759. https://doi.org/10.1016/j.buildenv.2018.07.033

Gagnon D, Kenny GP (2012) Does sex have an independent effect on thermoeffector responses during exercise in the heat? J Physiol 590:5963-5973. https://doi.org/10.1113/jphysiol.2012.240739

Gasparrini A (2011) Distributed lag linear and non-linear models in r: the Package Dlnm. J Stat Softw 43:1-20

Gasparrini A, Leone M (2014) Attributable risk from distributed lag models. BMC Med Res Methodol 14:55. https://doi.org/10.1186/ 1471-2288-14-55

Gasparrini A et al (2015) Mortality risk attributable to high and low ambient temperature: a multicountry observational study. Lancet 386:369-375. https://doi.org/10.1016/S0140-6736(14)62114-0
Huynen MMTE, Martens P (2015) Climate change effects on heatand cold-related mortality in the netherlands: a scenario-based integrated environmental health impact assessment. Int J Environ Res Public Health 12:13295-13320. https://doi.org/10.3390/ijerp h121013295

Jiao A et al (2019) Impact of summer heat on mortality and years of life lost: application of a novel indicator of daily excess hourly heat. Environ Res 172:596-603. https://doi.org/10.1016/j.envres. 2019.01.056

Kaciuba-Uscilko H, Grucza R (2001) Gender differences in thermoregulation. Curr Opin Clin Nutr Metab Care 4:533-536. https://doi. org/10.1097/00075197-200111000-00012

Kenney WL, Craighead DH, Alexander LM (2014) Heat waves aging and human cardiovascular health. Med Sci Sports Exerc 46:18911899. https://doi.org/10.1249/MSS.0000000000000325

Klepeis NE et al (2001) The National Human Activity Pattern Survey (NHAPS): a resource for assessing exposure to environmental pollutants. J Expo Sci Environ Epidemiol 11:231-252

Koppe C, Kovats S, Jendritzky G, Menne B (2004) Heat-waves: risks and responses. Health and global environmental change. WHO Regional Office for Europe, Copenhagen. https://apps.who.int/iris/ handle/10665/107552. Accessed 05 Jan 2021

Krummenauer L, Prahl BF, Costa L, Holsten A, Walther C, Kropp JP (2019) Global drivers of minimum mortality temperatures in cities. Sci Total Environ. https://doi.org/10.1016/j.scitotenv.2019. 07.366

Lee YS (2005) Gender differences in physical activity and walking among older adults. J Women Aging 17:55-70. https://doi.org/ 10.1300/J074v17n01_05

Ling-Shuang L, Dong-Hui J, Wen-Jun M, Tao L, Yi-Qing X, Xing-E Z, Chun-Liang Z (2020) The impact of non-optimum ambient temperature on years of life lost: a multi-county observational study in Hunan, China. Int J Environ Res Public Health. https:// doi.org/10.3390/ijerph17082699

Liu J et al (2020) Cause-specific mortality attributable to cold and hot ambient temperatures in Hong Kong: a time-series study, 2006-2016. Sustain Cities Soc. https://doi.org/10.1016/j.scs. 2020.102131

Lowe D, Ebi KL, Forsberg B (2011) Heatwave early warning systems and adaptation advice to reduce human health consequences of heatwaves. Int J Environ Res Public Health 8:4623-4648. https:// doi.org/10.3390/ijerph8124623

McArdle WD, Toner MM, Magel JR, Spinal RJ, Pandolf KB (1992) Thermal responses of men and women during cold-water immersion: influence of exercise intensity. Eur J Appl Physiol 65:265270. https://doi.org/10.1007/BF00705092

McArdle WD, Katch FI, Katch VL (2014) Exercise physiology, 8th edn. Wolters Kluwer, Amsterdam

McGinn R, Poirier MP, Louie JC, Sigal RJ, Boulay P, Flouris AD, Kenny GP (2017) Increasing age is a major risk factor for susceptibility to heat stress during physical activity. Appl Physiol Nutr Metab 42:1232-1235. https://doi.org/10.1139/apnm-2017-0322

McKee C (1989) Deaths in winter: can Britain learn from Europe? Eur J Epidemiol 5:178-182

Meehl GA, Tebaldi C (2004) More intense, more frequent, and longer lasting heat waves in the 21st century. Science 305:994-997. https://doi.org/10.1126/science.1098704

O’Neill MS, Zanobetti A, Schwartz J (2003) Modifiers of the temperature and mortality association in seven US cities. Am J Epidemiol 157:1074-1082. https://doi.org/10.1093/aje/kwg096

Planbureau voor de Leefomgeving (2016). Balans van de Leefomgeving. https://bit.ly/2UuP4NN. Accessed 11 June 2020

Pyrgou A, Santamouris M (2020) Article probability risk of heat-and cold-related mortality to temperature, gender, and age using GAM regression analysis. Climate. https://doi.org/10.3390/cli8030040 
Rahmstorf S, Coumou D (2011) Increase of extreme events in a warming world. Proc Natl Acad Sci 108:17905-17909. https://doi.org/ 10.1073/pnas. 1101766108

Rocklöv J, Forsberg B, Ebi K, Bellander T (2014) Susceptibility to mortality related to temperature and heat and cold wave duration in the population of Stockholm county. Sweden Global Health Action. https://doi.org/10.3402/gha.v7.22737

Tan CCS, Chin LKK, Low ICC (2020) Thermoregulation in the aging population and practical strategies to overcome a warmer tomorrow. Proteomics. https://doi.org/10.1002/pmic.201800468

The Japan Refrigeration and Air Conditioning Industry Association (2018). World air conditioner demand by region. https://www. jraia.or.jp/english/World_AC_Demand.pdf. Accessed 28 May 2021

Tobías A, Armstrong B, Gasparrini A (2017) Brief report: investigating uncertainty in the minimum mortality temperature. Epidemiology 28:72-76. https://doi.org/10.1097/EDE.0000000000000567

van Steen Y, Ntarladima AM, Grobbee R, Karssenberg D, Vaartjes I (2019) Sex differences in mortality after heat waves: are elderly women at higher risk? Int Arch Occup Environ Health 92:37-48. https://doi.org/10.1007/s00420-018-1360-1
Vargas NT, Chapman CL, Sackett JR, Johnson BD, Gathercole R, Schlader ZJ (2019) Thermal behavior differs between males and females during exercise and recovery. Med Sci Sports Exerc 51:141-152. https://doi.org/10.1249/MSS.0000000000001756

Wood SN (2006) Generalized additive models: an introduction with R. Chapman \& Hall. CRC, Boca Raton

Worfolk JB (2000) Heat waves: their impact on the health of elders. Geriatr Nurs 21:70-77. https://doi.org/10.1067/mgn.2000.107131

Yanovich R, Ketko I, Charkoudian N (2020) Sex differences in human thermoregulation: relevance for 2020 and beyond. Physiology 35:177-184. https://doi.org/10.1152/physiol.00035.2019

Yu W, Vaneckova P, Mengersen K, Pan X, Tong S (2010) Is the association between temperature and mortality modified by age, gender and socio-economic status? Sci Total Environ 408:3513-3518. https://doi.org/10.1016/j.scitotenv.2010.04.058

Publisher's Note Springer Nature remains neutral with regard to jurisdictional claims in published maps and institutional affiliations. 